\title{
Oral Immunotherapy in Children: Clinical Considerations and Practical Management
}

\author{
Brent Anderson \\ Lauren Wong \\ Bahman Adlou \\ Andrew Long \\ R Sharon Chinthrajah
}

Sean N Parker Center for Allergy and Asthma Research at Stanford University, Stanford University, Stanford, CA, USA
Correspondence: R Sharon Chinthrajah Sean N Parker Center for Allergy and Asthma Research at Stanford University, Stanford University, 240 Pasteur Dr BMI $\#$ I 454, Palo Alto, CA, USA

Tel +| $65052 \mid 7237$

$\mathrm{Fax}+16507240198$

Email schinths@stanford.edu

\begin{abstract}
Oral immunotherapy (OIT) in pediatric patients provides an alternative option to the current standard of care in food allergy, which is allergen avoidance and reactive treatment. Because patients are exposed to one or more food allergens during treatment, OIT is associated with adverse events and can be a cumbersome process for children, their caregivers, and clinicians. However, there have been an overwhelming number of studies that show high efficacy in both single- and multi-allergen OIT, and that quality of life is greatly improved for both patients and their families after undergoing immunotherapy. This review discusses clinical considerations for OIT in pediatrics, including efficacy and safety, practical management, and future directions of treatment. Keywords: food allergy, atopy, desensitization, tolerance, omalizumab, dupilumab, IgE, sustained unresponsiveness
\end{abstract}

\section{Introduction}

Approximately 6 million children in the United States alone have at least one food allergy (FA), placing the burden at nearly one in 13 children. ${ }^{1}$ There is compelling evidence that the prevalence of FA has increased in both Westernized and developing countries over the last few decades, making it an epidemic and a public health concern. ${ }^{2}$ Immunoglobulin (Ig) E-mediated FA is a serious and potentially life-threatening condition in children, generally characterized by an adverse immune response to common foods. ${ }^{3}$ The most common food allergens among children in the United States are peanut, cow's milk (CM), egg, wheat, shellfish, seafood, soy, and tree nuts, with most developing in the first or second year of life. ${ }^{1,2}$

The current standard of care for most of the food allergic population is food allergen avoidance and symptomatic treatment for acute allergic reactions with antihistamines and epinephrine auto-injectors. ${ }^{4}$ However, strict allergen avoidance is difficult, and approximately $40 \%$ of children with FA experience at least one FArelated emergency department visit in their lifetime. ${ }^{1}$ Additionally, quality of life (QoL) is impacted for a significant portion of children with FA due to constant anxiety, hypervigilance, and restricted diets. ${ }^{1}$ Among those with FA, $40 \%$ report multiple FAs, making allergen avoidance even more challenging. ${ }^{1}$ There is an increasing need for safe and effective treatments for FA.

Ongoing investigations of various forms of allergen immunotherapy, including oral, sublingual, and epicutaneous, are being studied for children with food allergies. ${ }^{5}$ Each strategy may be used as a monotherapy or combined with adjunct medications. During oral immunotherapy (OIT), individuals with FA are given oral doses of their offending food allergen(s) that are gradually increased over time, with the goal of increasing their 
sensitivity threshold. The effectiveness of FA treatments can be evaluated based on patients achieving desensitization or tolerance. Desensitization involves ingesting gradually increasing amounts of the food protein, with "desensitized" referring to those maintaining a regular schedule of ingestion to remain in a clinically non-reactive state. Tolerance is the ability to ingest an allergen without reaction, even after discontinuation of OIT for weeks to months. The term "sustained unresponsiveness (SU)" is often used when an individual remains tolerant to an allergen following a period of OIT withdrawal.

Here, we review the current status of OIT for single and multiple food allergens, the clinical considerations and management of OIT in pediatric patients, and the use of adjunctive medications during OIT.

\section{Efficacy of Oral Immunotherapy Single-Allergen Oral Immunotherapy}

To date, OIT has been found to be efficacious in desensitizing patients to peanut, CM, and hen's egg across multiple studies and is also being explored and used for a range of other food allergens. ${ }^{6}$ There have been a number of large clinical trials that have demonstrated the safety and efficacy of singleallergen OIT (Table 1). While the fundamental methodology of OIT is shared across the majority of treatment protocols, there remains a significant level of variability. Most OIT protocols start with an initial rapid escalation phase over 12 days, reaching a dose in the range of several milligrams (Figure 1). ${ }^{7,8}$ This is followed by incremental dose increases every 1-2 weeks until a maintenance dose is reached or doselimiting symptoms are observed. The amounts for maintenance doses vary, but participants generally continue daily allergen ingestion at home for an indefinite period of time in order to maintain desensitization. While some protocols aim to desensitize an individual to amounts that are consumed ad lib in natural diets, others aim to target much lower amounts, such as those that may be consumed upon accidental ingestion. ${ }^{9}$ The goal of OIT may be driven by the desired outcome of the participant and/or guardians whether that be incorporation into the diet or simply day-to-day protection.

In a recent study of raw egg-white powder OIT in children aged 6-17 years with hen's egg allergy, higher levels of eggwhite specific $\operatorname{IgE}$ ( $\mathrm{sIgE}$ ) and sensitization to multiple components of egg allergen at baseline were associated with decreased likelihood of tolerating the maximum daily eggwhite protein dose at 8 months. ${ }^{10}$ However, with prolonged treatment of up to 18 months, $72 \%$ of all participants were able to tolerate the maximum daily dose. Furthermore, most participants (88\%) continued to successfully consume eggs as part of their daily diet after 18 months. These findings have been supported by data aggregated from a wide range of sources, indicating a trend that frequent and increasing exposure to egg over 1-2 years in egg-allergic children builds tolerance in almost everyone. ${ }^{11}$ Beyond egg allergy, improved efficacy with a longer duration of OIT has also been shown with CM allergy. ${ }^{12}$

The majority of clinical trials investigating single-allergen OIT have been centered on peanut allergy. A clinical trial was conducted with preschool-aged children for peanut OIT (POIT) in a real-world multicenter setting. ${ }^{13}$ Of the 270 patients, 243 were able to reach a target maintenance dose of $300 \mathrm{mg}$ peanut protein, and the treatment-associated symptoms experienced were generally mild. The IMPACT study assessed peanut-allergic children aged 1-3 years who received either peanut or placebo OIT for 134 weeks. ${ }^{14}$ Data from the trial presented at the 2020 meeting of the American Academy of Allergy, Asthma \& Immunology highlighted that desensitization occurred in the majority of POIT participants (71\%) compared to placebo ( $2 \%)$, with the achievement of tolerance in a small subset of patients. Successful desensitization and tolerance were observed to be associated with decreases in peanut sIgE and increases in peanut-specific and component IgG4.

The PALISADE study investigated AR101, a peanut derived oral biologic drug that gradually escalates to a daily maintenance dose of $300 \mathrm{mg}$ peanut protein. ${ }^{15}$ The study found that after one year of active treatment, $67.2 \%$ of children aged 4-17 years with peanut allergy who could tolerate less than $30 \mathrm{mg}$ of peanut protein at baseline were able to tolerate at least $600 \mathrm{mg}$ during an oral food challenge (OFC) at the study conclusion. Daily peanut intake lowered the severity of allergic symptoms observed at the end-of-study OFC. The ARTEMIS trial observed similar results. ${ }^{16}$ Participants from PALISADE entered a follow-up study to assess the effects of AR101 dosing for an additional 12 or 18 months. ${ }^{17}$ Participants displayed continued immunological changes, including decreases in peanut sIgE, suggesting progressive desensitization and immunomodulation driven by increased duration of allergen exposure. After 2 years, $80.8 \%$ of children who continued daily dosing were found to tolerate $2000 \mathrm{mg}$ peanut protein during the endof-study $\mathrm{OFC}$ - a drastic increase from the baseline mean tolerated dose. $^{18}$

AR101, now known as Palforzia ${ }^{\circledR}$ [Peanut (Arachis hypogaea) Allergen Powder-dnfp], is the first and only treatment currently approved by the US Food and Drug Administration for peanut allergy. ${ }^{19}$ Approved in January 2020, Palforzia is 
Table I Summary of Recent Studies in OIT

\begin{tabular}{|c|c|c|c|c|c|c|}
\hline Study & $\begin{array}{c}\text { Food } \\
\text { Allergen }\end{array}$ & $\begin{array}{c}\text { Participant } \\
\text { Age }\end{array}$ & $\begin{array}{l}\text { Number of } \\
\text { Participants }\end{array}$ & Dosing Protocol & $\begin{array}{l}\text { Duration of } \\
\text { OIT }\end{array}$ & Key Outcomes and Conclusions \\
\hline $\begin{array}{l}\text { Chinthrajah } \\
\text { et al } 2019^{26}\end{array}$ & Peanut & $7-55$ years & 120 & $\begin{array}{l}\text { Build-up to maintenance dose } \\
\text { of } 4000 \mathrm{mg} \text {, then } 300 \mathrm{mg} \\
\text { continued dosing or placebo }\end{array}$ & $\begin{array}{l}\text { I04 weeks, then } \\
\text { lower dose for } \\
\text { additional } 52 \\
\text { weeks }\end{array}$ & $\begin{array}{l}\text { Peanut OIT can successfully desensitize } \\
\text { patients up to } 4000 \mathrm{mg} \text {. }\end{array}$ \\
\hline $\begin{array}{l}\text { Vickery et al } \\
2021^{18}\end{array}$ & Peanut & 4-17 years & 358 & $\begin{array}{l}300 \mathrm{mg} \text { with daily or non-daily } \\
\text { dosing }\end{array}$ & $\begin{array}{l}\text { An additional } 28 \text { - } \\
56 \text { weeks after } \\
\text { updosing and } 24 \\
\text { weeks } \\
\text { maintenance }\end{array}$ & $\begin{array}{l}\text { Daily dosing cohorts had higher } \\
\text { desensitization rates. Continued allergen } \\
\text { intake past I year of therapy is beneficial in } \\
\text { sustaining OIT efficacy and } \\
\text { immunomodulation. }\end{array}$ \\
\hline $\begin{array}{l}\text { Sugiura et al } \\
2020^{9}\end{array}$ & $\begin{array}{l}\text { Egg, milk, } \\
\text { and } \\
\text { wheat }\end{array}$ & $4-8$ years & 216 & $\begin{array}{l}\text { Initial dose based on individual } \\
\text { OFC results, then escalated to } \\
\text { I0x greater than initial dose of } \\
\text { individual allergens }\end{array}$ & I year & $\begin{array}{l}\text { Slow low-dose OIT showed efficacy and only } \\
\text { a small portion of participants experienced } \\
\text { allergic symptoms. It is a promising therapy for } \\
\text { patients with severe FAs. }\end{array}$ \\
\hline $\begin{array}{l}\text { Andorf et al } \\
2018^{42}\end{array}$ & Multifood & $4-15$ years & 48 & $\begin{array}{l}\text { Received omalizumab or } \\
\text { placebo together with mOIT }\end{array}$ & 28 weeks & $\begin{array}{l}\text { A greater percentage of participants who } \\
\text { received omalizumab passed DBPCFCs and } \\
\text { tolerated } 4 \mathrm{~g} \text { protein of their FAs. } \\
\text { Omalizumab enables more rapid } \\
\text { desensitization in mOIT. }\end{array}$ \\
\hline $\begin{array}{l}\text { Andorf et al } \\
2019^{52}\end{array}$ & Multifood & $5-22$ years & 70 & $\begin{array}{l}\text { Received omalizumab and } \mathrm{m} \\
\text { OIT for } 2-5 \text { allergens at doses } \\
\text { up to } 2 \mathrm{~g} \text { per allergen, followed } \\
\text { by } 0 \mathrm{mg}, 300 \mathrm{mg} \text {, or I g }\end{array}$ & $22-28$ weeks & $\begin{array}{l}\text { Desensitization was achieved with } \\
\text { omalizumab and mOIT. Maintenance of } \\
\text { desensitization was more effective with } \\
\text { maintenance of } 300 \mathrm{mg} \text { or I g dose than } \\
\text { discontinuation of OIT. }\end{array}$ \\
\hline
\end{tabular}

Abbreviations: DBPCFC, double-blind placebo-controlled food challenge; FA, food allergy; mOIT, multi-allergen oral immunotherapy; OFC, oral food challenge; OIT, oral immunotherapy.

available for children aged 4-17 years with peanut allergy. The product desensitizes children over time through an initial dose escalation of peanut protein in a healthcare setting, followed by up-dosing and a daily maintenance dose of $300 \mathrm{mg}$ peanut protein in the form of powder mixed into soft food. While the approval of Palforzia ${ }^{\circledR}$ is a clear advancement for the food allergy community, there are still many unmet needs for most FA patients.

Clinical Considerations: OIT is an effective treatment for food allergies in children and has been successfully performed for a wide variety of allergens in clinical trials. These allergens include, but are not limited to, peanut, tree nuts, egg, wheat, CM, shellfish, seafood, and soy.

\section{Multi-Allergen Oral Immunotherapy}

Given the prevalence of those with multiple food allergies, multi-allergen OIT (mOIT) is an approach of growing interest for such individuals. However, studies of mOIT have been limited due to safety concerns. Bégin et al investigated the safety and feasibility of patients consuming up to five foods in their OIT mix, and found rates of reaction per dose did not differ significantly between the mOIT and POIT arms. ${ }^{20}$ A recent retrospective review comparing peanut and mOIT also demonstrated the safety of combining multiple foods into one OIT mix. ${ }^{21}$ All patients underwent a dose escalation phase, after which $85 \%$ of POIT patients and $80 \%$ of mOIT patients reached the maintenance dose. The median time to reach maintenance dose, changes in SIgE levels, and percentage of patients requiring epinephrine during treatment were comparable between both groups.

Clinical Considerations: Multi-allergen OIT is a promising approach for children with more than one food allergy. Clinical trials have demonstrated a safety profile comparable to single-allergen OIT, and treating multiple allergies simultaneously can decrease patient burden significantly.

\section{Impact of Age}

Oral immunotherapy has shown efficacy across children of all ages, including those less than one year old. ${ }^{14,22}$ Some research has suggested younger age may be a more optimal 


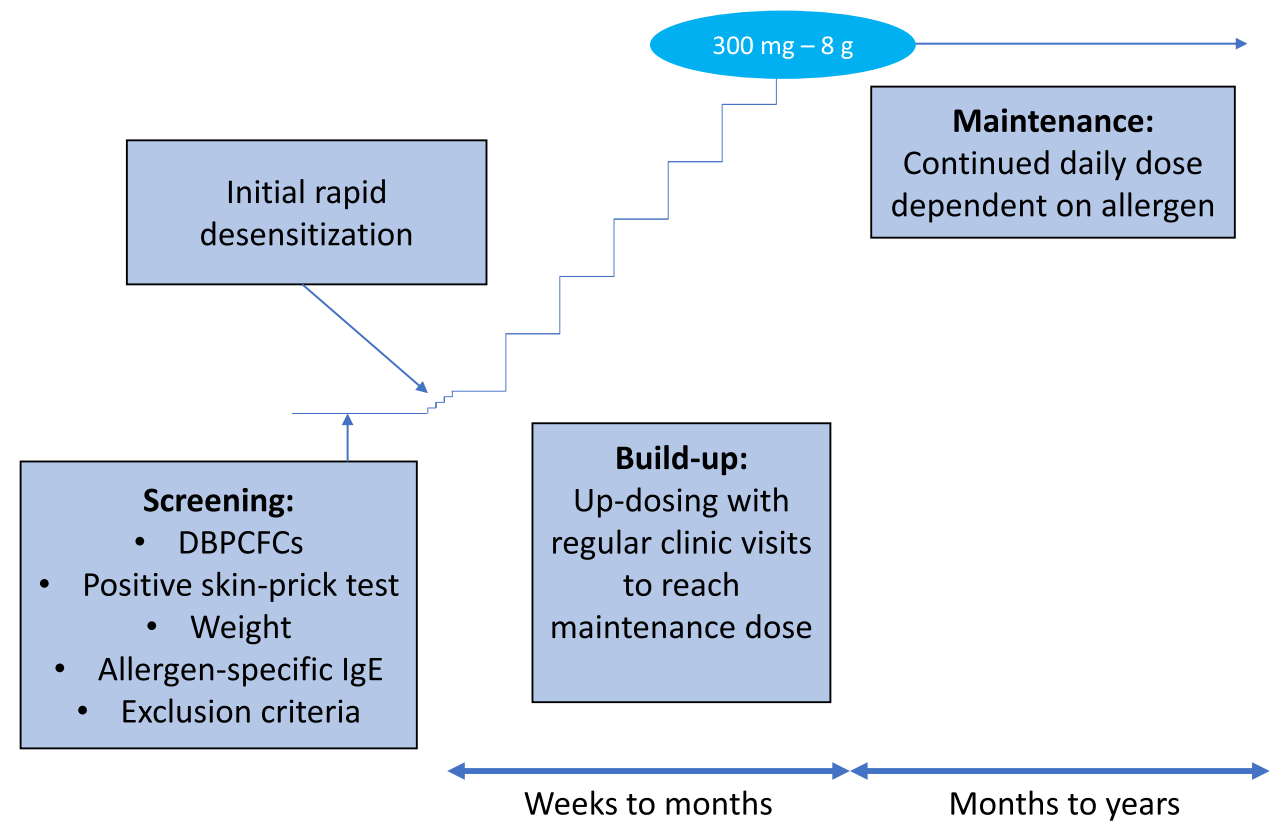

Figure I Typical single-food OIT protocol.

time to introduce OIT as food sIgE production commonly starts in infancy, and higher IgE levels are strongly correlated with the clinical presentation of allergy. ${ }^{22}$ Early exposure to peanuts in infants with severe eczema and/or egg allergy can significantly reduce the prevalence of peanut allergy, compared to those who completely avoid peanuts in the first 60 months of life. ${ }^{23}$ Vickery et al evaluated early intervention OIT with high and low doses of peanut protein in recently diagnosed peanut allergic children aged 9 to 36 months. ${ }^{22}$ Overall, $78 \%$ of participants achieved SU to peanut 4 weeks after discontinuing OIT, and all had a significant decrease in peanut sIgE levels. There were no significant differences in allergic immune responses between the groups. These findings support the hypothesis that early intervention with low-dose oral exposure can disrupt peanut allergy and help facilitate the introduction of peanut into the diet of young children with clinical disease expression. Even beyond the first few years of life, POIT can be significantly more effective in children than adults. ${ }^{15}$

Clinical Considerations: Beginning OIT at an early age may result in improved results from treatment; initiation should not be delayed due to young age alone.

\section{Maintaining Desensitization}

When providing OIT, a key factor to consider is the longterm effectiveness and likelihood of achieving SU.
A patient is considered to have achieved SU when they retain their desensitization after a period of OIT avoidance. Sustained unresponsiveness was evaluated in children aged 1-16 years who underwent POIT for up to 5 years. ${ }^{24}$ Patients consumed up to $4000 \mathrm{mg}$ peanut protein per day before stopping OIT for 4 weeks; one month after stopping OIT, 12 of 24 patients were able to consume 5000 $\mathrm{mg}$ cumulative peanut protein at $\mathrm{OFC}$ as well as one serving of peanut butter (8000-10000 mg protein) later the same day. Nagakura et al recruited participants aged 518 years who were given incrementally increasing peanut protein doses followed by a $133 \mathrm{mg}$ protein daily maintenance dose for a year. ${ }^{25}$ After one year, patients avoided peanut for 2 weeks and were subsequently challenged to $795 \mathrm{mg}$ of peanut protein. Thirty-three percent of children in the OIT group achieved SU, defined as tolerance of the full $795 \mathrm{mg}$, after 2 weeks of peanut avoidance, compared to none in the control group. The POISED study was a randomized double-blind, placebo-controlled Phase II trial that investigated sustained responses in 120 peanut allergic children and adults. ${ }^{26}$ POISED involved desensitizing participants to $4 \mathrm{~g}$ of peanut or placebo over the first year, maintaining $4 \mathrm{~g}$ peanut or placebo for one year, and then testing sustained responses to $300 \mathrm{mg}$ daily or full avoidance over the third year. It was shown that $85 \%$ of peanut allergic participants who received peanut oral immunotherapy were able to tolerate $4 \mathrm{~g}$ of peanut at the end of 2 years compared to $4 \%$ who received placebo. 
However, when the dose was decreased to $300 \mathrm{mg}$ maintenance or complete avoidance, peanut allergic participants lost their non-reactivity to $4 \mathrm{~g}$, and continued to lose their protection over the course of the 3rd year. Only $35 \%$ of those randomized to $0 \mathrm{mg}$ were still able to tolerate $4 \mathrm{~g}$ of peanut at 117 weeks and $13 \%$ achieved SU at 156 weeks. The IMPACT study showed desensitization drop from a rate of $71 \%$ to $21 \%$ after 26 weeks off POIT. ${ }^{14}$ Similar findings have been reported for egg OIT. ${ }^{27}$ After receiving three months of egg OIT with a maintenance dose of at least one undercooked egg every 48 hours, rates of SU were evaluated after one month of egg avoidance. Upon challenge, 11 out of $30(37 \%)$ children were able to pass the OFC with a cumulative dose of $280.08 \mathrm{mg}$ egg protein without any symptoms, while only 1 out of $31(3 \%)$ children passed the challenge in the control group. Despite the significantly higher rate of success in those that had previously received OIT, it is clear that loss of desensitization remains a pressing issue.

While desensitized patients risk loss of tolerance to an allergen in the absence of continued allergen dosing, many patients do successfully incorporate the allergen into their daily diets. While long-term daily dosing is an excellent option for many children, it is not without risk, and adherence can be an issue. Emerging data, however, suggest that patients may be able to reduce the amount of protein regularly consumed after desensitization while still maintaining tolerance thresholds. Nachshon et al studied peanut allergic patients aged 4 years and older who had built up to a daily dose of $3000 \mathrm{mg}$ peanut protein. ${ }^{28}$ Patients were instructed to continue consuming either 1200 or $3000 \mathrm{mg}$ daily and were re-challenged to $3000 \mathrm{mg}$ after 6 months or longer. Of the patients who consumed $3000 \mathrm{mg}$ peanut protein daily, 22/22 passed the $3000 \mathrm{mg}$ OFC, compared to $63 / 64$ of the patients who consumed $1200 \mathrm{mg}$ daily. Importantly, discontinuation of treatment during maintenance dosing was significantly lower in the $1200 \mathrm{mg}$ group $(3.9 \%)$ than the $3000 \mathrm{mg}$ group $(31.4 \%)(\mathrm{p}=0.001)$. These findings are supported by additional studies that have demonstrated similar efficacy with maintenance dosing and subsequent re-challenges; however, the optimal balance between minimizing post-OIT dosing while maximizing the durability of desensitization remains unclear. ${ }^{26,29,30}$ In the POISED study, those continuing to receive $300 \mathrm{mg}$ peanut protein daily after completing POIT to $4 \mathrm{~g}$ peanut protein gradually lost the ability to tolerate $4 \mathrm{~g}$ of peanut; $54 \%$ were able to tolerate $4 \mathrm{~g}$ after 3 months on a decreased dose compared to $37 \%$ at the end of the year. ${ }^{26}$
Clinical Considerations: Given existing data, additional research is clearly needed to develop better strategies for achieving long-term tolerance. While a small portion of patients are able to maintain full desensitization in the absence of continued dosing, allergists seldom advise allergic patients to completely stop their OIT or regular intake of food allergen for several years after the treatment. Allergists and pediatricians are expected to decide whether to initiate OIT after several informed discussions with the patients and their families in which realistic expectations can be set with regard to next steps after OIT.

\section{Safety Considerations}

\section{Frequency and Severity of Adverse Events} Although OIT has shown efficacy in reducing the risk of children reacting to accidental ingestion of an allergen, safety issues continue to be a concern. Children undergoing OIT are at greater risk of experiencing IgE-mediated local or systemic allergic reactions whether home- or clinic-dosing. ${ }^{31}$ However, there is significant variation in the presentation of OIT-associated AEs in both frequency and severity. Much of this variation may be driven by differences in rates of dose escalation, total daily allergen dose, and traits of the individual allergen and patient.

The ARTEMIS trial reported that most children receiving relatively low-dose POIT (ie, $300 \mathrm{mg}$ peanut protein daily) reported the majority of AEs as mild or moderate (mild, 50\%; moderate, 48\%; and severe, $1 \%$ ). ${ }^{16}$ A study of OIT for the treatment of egg allergy in children demonstrated similar findings, with no AEs classified as severe. ${ }^{32}$ The majority were oropharyngeal. A meta-analysis reviewed 27 studies in which children underwent POIT. ${ }^{33}$ Treatment discontinuation due to AEs occurred in $6.6 \%$ of children, and epinephrine was required at a rate of 2.0 per 10,000 doses. It is important to note that several of these studies included a co-treatment with medications, such as antihistamines or omalizumab; those who received cotreatments had a lower risk of study discontinuation.

Although the majority of patients will experience at least one AE during OIT, data suggest that the incidence of AEs is transient and decreases with time on OIT. While AEs were reported in $25 \%$ of total doses during egg OIT, this decreased to $8.3 \%$ of doses after 10 months of OIT. ${ }^{32}$ The POISED study also showed that allergic reactions related to POIT improved the longer the participants stayed on peanut OIT. ${ }^{26}$ Rates of reactions to accidental ingestions also decreased over time on POIT $(9 \%$ in the first year; $2 \%$ in second year; $3 \%$ in third year in POIT) compared to $12-16 \%$ in placebo. 
Beyond IgE-mediated AEs, non-allergic or non-IgEmediated symptoms associated with the gastrointestinal system are an additional risk occasionally observed in those undergoing OIT. Of note, eosinophilic esophagitis (EoE) has been identified as a rare, but long-term complication of OIT. ${ }^{34,35}$ A gastrointestinal sub-study of the POISED trial that performed serial upper endoscopies of 20 adults demonstrated that asymptomatic baseline eosinophilia in the esophagus is common in adults with peanut allergy. Further, in those developing eosinophilia in the esophagus during POIT, the occurrence was largely asymptomatic and resolved with continued POIT. ${ }^{36,37}$ These studies highlight that eosinophilia can be common in allergic individuals. The true incidence of EoE is unknown because it requires clinical symptoms and histological confirmation. Endoscopies are invasive procedures and minimally invasive methods to track eosinophils within the esophagus are needed to truly understand the incidence of $\mathrm{EoE}$ within children and adults undergoing OIT. Providers should be vigilant in observing for signs indicative of such occurrences. In young children, refusal to eat, abdominal pain, recurrent nausea, and emesis may be signs of EoE, whereas in older children and adolescents, dysphagia is the predominant symptom. Patients should be referred to specialists if such symptoms are observed and OIT should be discontinued; unlike IgE-mediated AEs that often resolve with continued OIT, EoE has not been shown to be transient during treatment.

Clinical Considerations: Adverse events are to be expected in patients undergoing OIT and vary from patient to patient; however, they are usually mild to moderate in severity and tend to decrease with time on OIT. In addition to adjusting the dose escalation scheme with respect to individual patient tolerance, providing this information may be beneficial in motivating patients to continue with treatment in the event of AEs, especially during the early stages of treatment.

\section{Immunologic Risk Factors}

There are certain underlying biomarkers and health conditions that may be associated with higher likelihood and/ or severity of AEs during an OFC or OIT. With respect to OFCs, one study found that a history of atopic dermatitis and multiple food allergies were associated with a higher risk of positive OFCs. ${ }^{38}$ Certain biomarkers, such as skin prick tests or $\operatorname{sIgE}$ values, above certain thresholds may also be useful in predicting positive OFCs. Data suggest that the majority of those aged 5 years and older who developed severe symptoms during
OFCs had significantly higher allergen sIgE titers, history of anaphylaxis, and/or older age. ${ }^{39} \mathrm{~A}$ retrospective chart review of 428 participants also found that a history of asthma was associated with a significantly greater risk of severe reaction. ${ }^{40}$ A tool was developed by Chinthrajah et al to predict allergic reaction severity during peanut challenge, identifying three main variables that increased risk of a severe reaction: higher ratio of percentage of CD63 ${ }^{\text {hi }}$ stimulation with peanut to percentage of CD63 ${ }^{\text {hi }}$ anti-IgE, history of exercise induced asthma, and lower forced expiratory volume in 1 second to forced vital capacity ratio. ${ }^{41}$ Additional data from the POISED study of POIT identified similar associations between higher baseline peanut $\operatorname{SIgE}$ and an increased frequency of AEs during active $\mathrm{OIT}^{26}$

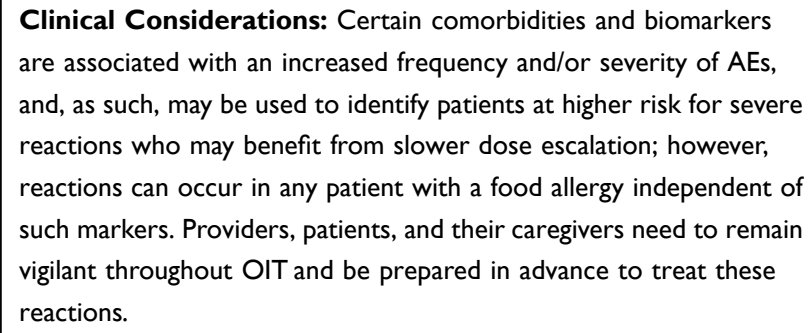

\section{Adjunct Therapies}

Although OIT has the potential to treat IgE-mediated FA, it faces limitations such as frequent food allergic reactions, patient non-tolerability, and lack of SU. Therefore, the current literature is focused on improving the safety and efficacy of therapy to develop the optimal FA treatment plan. In recent years, there has been interest in the concomitant administration of highly specific biologic agents to patients before and/or during OIT in an effort to reduce the rate and severity of OIT-associated AEs as well as expedite the desensitization process. The most studied biologic to date is omalizumab.

\section{Omalizumab}

Omalizumab is an anti-IgE medication that works by selectively targeting and binding free IgE, which in turn inhibits the binding of free $\operatorname{IgE}$ to its receptor expressed on mast cells and basophils (FceRI) as well as CD23 on $\mathrm{B}$ cells and antigen-presenting cells. ${ }^{42,43}$ Anti-IgE treatment is intended to suppress and impede pro-inflammatory pathways, which may increase the allergenic burden required to induce an allergic reaction. Omalizumab is an 
approved therapy for severe allergic asthma and chronic idiopathic urticaria. ${ }^{44}$ In the field of FA, omalizumab has been evaluated as a monotherapy, as well as an adjunct to single- and mOIT due to the non-allergen-specific nature of its IgE binding. ${ }^{42,45-52}$ In evaluating the immunological mechanisms of omalizumab, basophil responses have been measured from blood samples of patients with $\mathrm{CM}$ allergy. ${ }^{53}$ Notably, patients with basophil reactivity above the $40 \%$ threshold were much less likely to show symptoms on allergen exposure if they had received omalizumab. Omalizumab is able to suppress basophil activation, and, thus, has been proposed as an adjunct to therapy in patients with higher levels of baseline basophil activity who may be more difficult to treat.

Improvements in OIT safety through omalizumab are readily observed in the literature. In one study, omalizumab was administered according to asthma dosing guidelines for 8 weeks prior to the start of mOIT, as well as during the first 8 weeks of dosing (Figure 2). ${ }^{42}$ The percentage of total doses associated with one or more AEs was significantly lower in those who received omalizumab compared to placebo $(27 \%$ vs $68 \%, p=0.0082)$ during weeks 8-16. Among those in the omalizumab arm, AEs did not increase once omalizumab was withdrawn. Similarly, Wood et al administered omalizumab for 4 months prior to CM OIT; the percentage of doses associated with AEs was also less in the omalizumab group when compared to placebo $(2.1 \%$ vs $16.1 \%$; $\mathrm{p}=$ $0.0005) .{ }^{46}$ In an additional study of patients with severe CM allergy receiving omalizumab, all patients were able to tolerate a $150 \mathrm{~mL}$ dose of raw milk after 2 months, and reactions observed were mild without the need for epinephrine. $^{54}$

While the addition of omalizumab to OIT does not appear to increase the proportion of patients reaching maintenance and desensitization independent of time, data suggest that omalizumab use may enable more rapid OIT dose escalation and significantly reduce time-to-maintenance given its ability to transiently increase the threshold of reaction and suppress the incidence of AEs. ${ }^{46}$ In a Phase I OIT desensitization trial in children with clinical reaction to $\mathrm{CM}$, the combination of omalizumab with OIT resulted in rapid milk dose escalation in most of the participants, with $90 \%$ tolerating relatively large amounts of milk in their diet $(\geq 8000 \mathrm{mg} / \mathrm{d}) .{ }^{51}$ Further research into the use of omalizumab for CM allergy has demonstrated that, in children given omalizumab followed by 24 weeks of OIT with microwave-heated CM, all children in the omalizumab group achieved desensitization 8 weeks after the medication was discontinued compared to none in the untreated group. ${ }^{55}$ Other placebo-controlled clinical trials evaluating the benefits of omalizumab as an adjunct therapy to $\mathrm{CM}$ or POIT found supported these findings; not only did the use of the biologic diminish the rate of AEs but additionally allowed

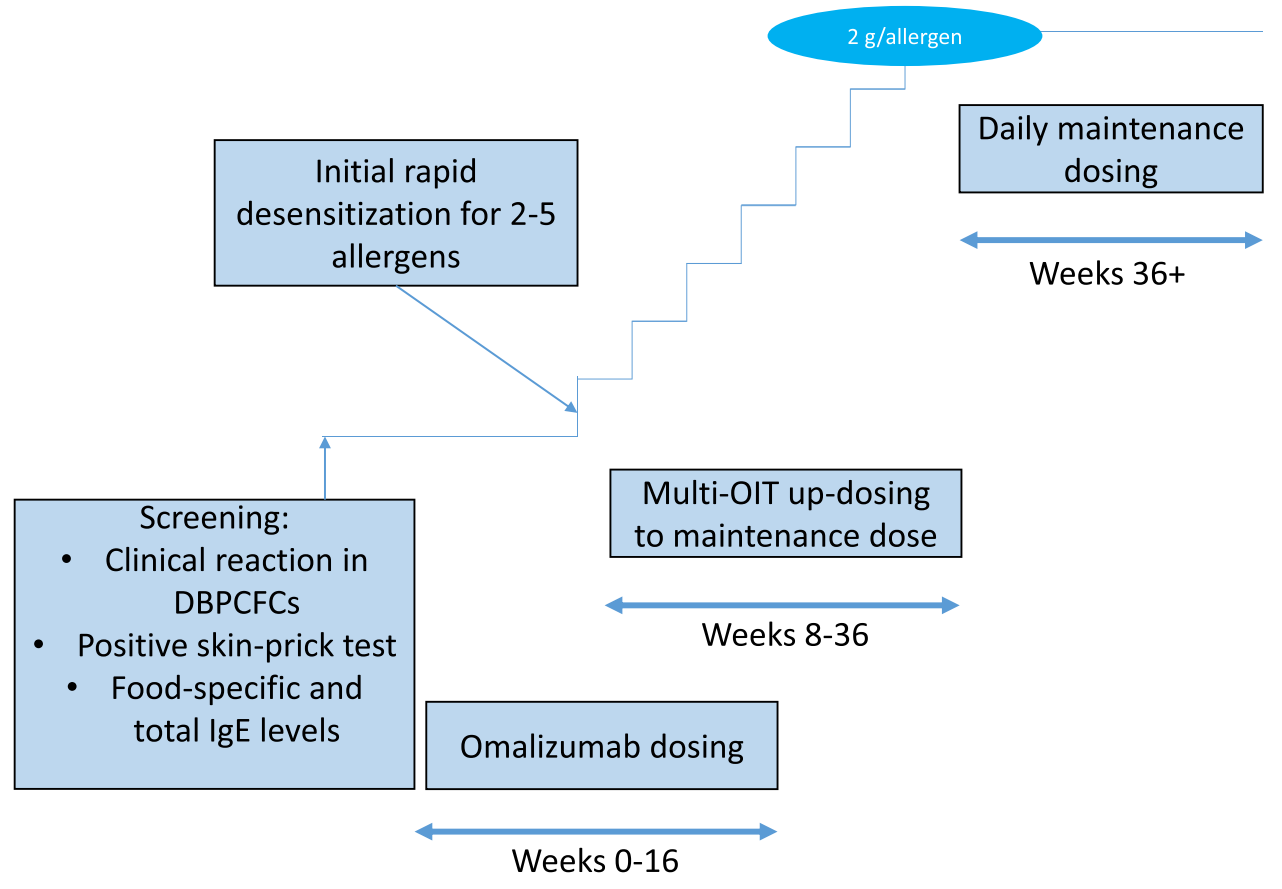

Figure 2 Example of multi-OIT protocol with omalizumab. 
for increased rates of OIT dose escalation. ${ }^{45,46,49}$ Most omalizumab patients (72\%) were able to tolerate a $2000 \mathrm{mg}$ OFC of peanut after only 8 weeks of POIT, compared to $12 \%$ of placebo patients. ${ }^{45}$ The application of omalizumab in the setting of mOIT has demonstrated similar results, including shortened time-to-maintenance allergen dosing, greater rates of desensitization at given time points, and decreased treatment-associated AEs compared to placebo. ${ }^{42,50,52}$

Clinical Considerations: Omalizumab has been shown to be an excellent addition to standard OIT, enabling more rapid dose escalation and decreasing the frequency of AEs. Nevertheless, given enough time, the proportion of patients reaching maintenance OIT and desensitization is similar with or without the use of omalizumab.

\section{Future Adjunct Therapies}

While omalizumab has shown promise in OIT, additional research into alternative co-therapies is needed to help further mitigate OIT-associated risks. Multiple nonallergen-specific biologics have been approved in recent decades for atopic diseases (previously reviewed in detail by Long et al), each targeting key antibodies and cytokines that overlap with the allergic pathway; however, these biologics are not yet approved for FA. ${ }^{56}$

Dupilumab has gained considerable interest in the field of FA treatment over the last several years. Dupilumab is a human monoclonal antibody targeting and binding the interleukin- (IL) $4 \alpha$ receptor, thus acting as a dual inhibitor to IL-4 and IL-13 signaling. ${ }^{57}$ By inhibiting these pro-inflammatory cytokines, the use of dupilumab is intended to reduce allergic reactions to allergens. Although currently approved for use in other atopic diseases, case reports have indicated decreased reactions to food allergens in those receiving dupilumab with comorbid FA. ${ }^{56,58}$ Two phase II studies are currently assessing the impact of dupilumab as an adjunct to $\mathrm{CM}$ or POIT in hopes of improving rates of desensitization and reducing dose-limiting reactions while evaluating the overall tolerability profile. ${ }^{59,60}$ An additional multi-site placebo-controlled phase II study is currently underway comparing the safety and efficacy of dupilumab, omalizumab, or a combination of both as adjunct therapies to mOIT in participants with peanut and at least one other food allergy. ${ }^{61}$
Clinical Considerations: The use of adjunct medications with OIT shows great promise, but at the present time, additional research is needed to better define their optimal use outside the clinical research space.

\section{Additional Considerations Patient-Centered Treatment}

It is important for clinicians to hold discussions with the patient and their families prior to initiating OIT treatment. Patient counseling and providing a written plan to avoid or reduce AEs have been shown to be beneficial. ${ }^{62}$ Clinical considerations should include the requirements of the treatment protocol to construct a patient-centered OIT treatment with a clear objective (eg, protection against accidental exposure vs incorporation into the diet) prior to protocol initiation. ${ }^{63} \mathrm{~A}$ shared decision-making process encourages dialog between patients, providers, and caregivers, discussing risks and benefits of treatment, as well as goals for therapy and potential treatment barriers (Figure 3). This can help patients and their families make an informed decision regarding therapy. Treatment compliance is a critical factor in driving the efficacy of OIT. Providers should maintain consistent communication with patients and their families, as well as attempt to offer flexible scheduling of clinic visits to accommodate patients' and their families' needs while balancing clinician availability and their clinic's capacities.

As previously detailed, mild-to-severe allergic reactions can occur during OFCs and OIT in children, and families, allergists, and their trained staff are first in line to manage these situations. Allergic symptoms are expected to occur within a few hours of scheduled dosing, when a patient is being observed. ${ }^{64}$ Additionally, there are a number of activities that may place the participant at increased risk of $\mathrm{AE}$ following dosing, such as exercising directly before or after a dose. Thus, clinicians must provide a detailed precautionary protocol in an attempt to mitigate those allergic reactions in children undergoing OIT (Table 2). Aversion to the allergen and dose avoidance are common in children, potentially manifesting due to previously experienced AEs, which may lead to withdrawal from treatment. ${ }^{65}$ While a few days of OIT discontinuation may not impact the efficacy of the treatment, longer breaks in OIT dosing can lead to loss of desensitization. In such cases, the clinician must re-assess the patient to determine the safest strategy for resuming OIT. 


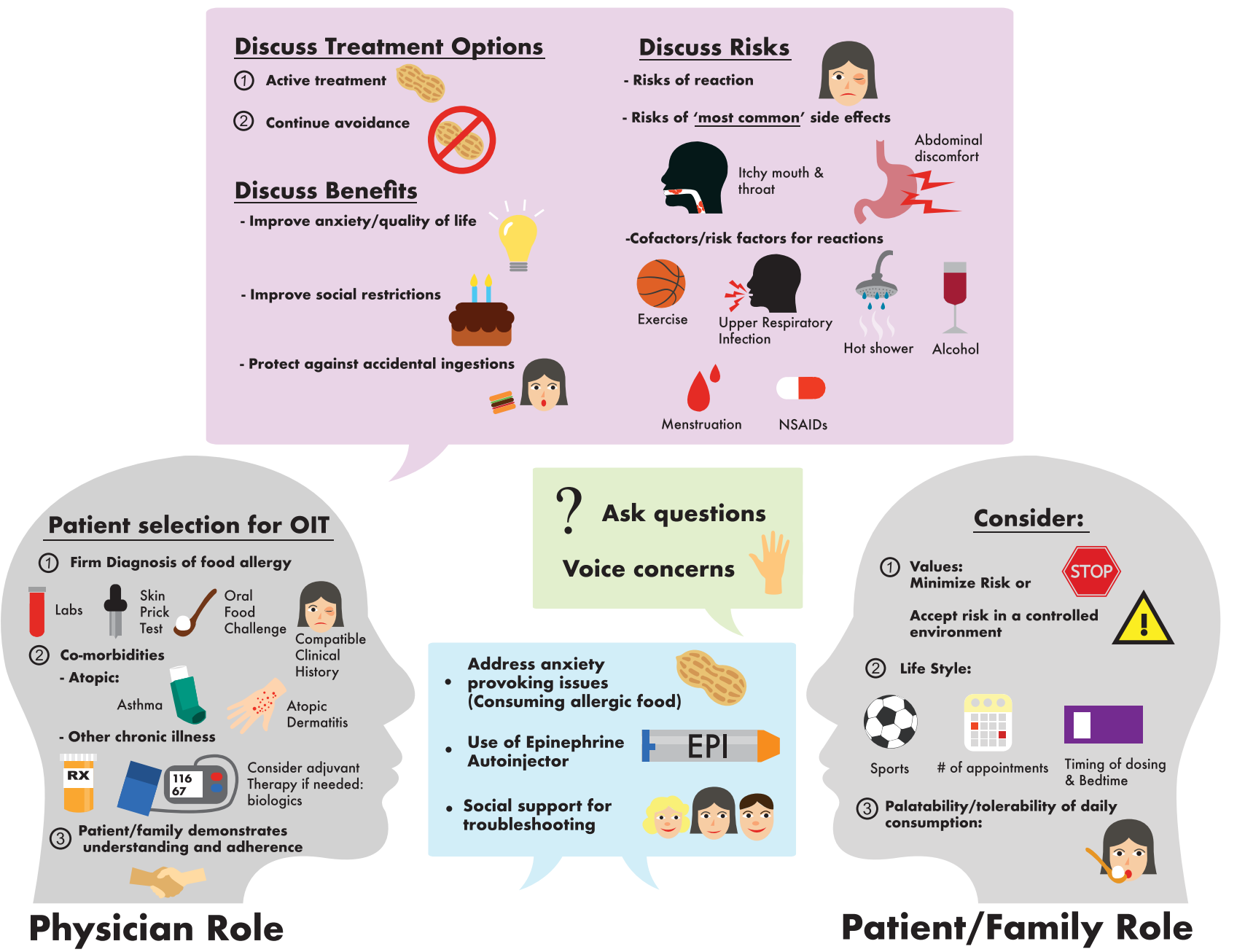

Figure 3 Shared decision-making with patients and families. Reprinted from World Allergy Organ J, I3(8), Chinthrajah RS, Cao S, Dunham T, et al. Oral immunotherapy for peanut allergy: the pro argument. 100455, Copyright 2020, with permission from Elsevier. ${ }^{63}$

Clinical Considerations: Pediatricians and allergists are in a key position to motivate children and their families to follow the treatment plan, as well as assess for potential issues in compliance early and often. A shared decision-making process is an excellent way to empower patients and their families to become involved in the treatment from the very beginning.

\section{Practical Considerations}

There are no major differences in emergency preparedness when considering OFCs or OIT dosing, including the recognition and treatment of anaphylaxis. A predetermined anaphylaxis protocol must already be in place prior to dosing, and a maintained emergency cart should be readily available and adequately stocked. Clinicians and their teams must be accessible to patients and guardians around-theclock to provide guidance in case of allergic reactions and other non-dose-related situations, such as illness, with respect to both reactive treatment and how to best proceed with OIT dosing. In some cases, dosing may require temporary modification. Minor and transient reactions such as perioral hives or oral itch are generally not dose-limiting allergic symptoms and do not require dose-reduction unless they become persistent or progress. ${ }^{6,15}$ Clinicians should educate the patients and families to expect these mild symptoms and offer potential strategies to counter them in order to reduce anxiety associated with the treatment. For example, oral itch can often be resolved when followed by food, beverage, or ice chips. Allergic reactions could occur by reaching reactive threshold, or because cofactors, such as physical activity surrounding a dose, have reduced the previously tolerated threshold. If the cofactor(s) cannot be avoided, then the allergist should consider halving the allergen dose for several days. ${ }^{66}$ In the absence of any identifiable cofactors despite the presence of new onset AEs to 
Table 2 General Considerations and Guidance for Providers in the Practical Management of Patients Undergoing OIT

\begin{tabular}{|c|c|c|}
\hline Area & Specific Case & Allergist/Pediatrician Recommendations \\
\hline \multirow{12}{*}{$\begin{array}{l}\text { General } \\
\text { Guidance }\end{array}$} & \multirow[t]{4}{*}{ General Advice } & Doses should be taken with a meal or a snack \\
\hline & & $\begin{array}{l}\text { Refrain from physical activity, hot showers, or otherwise any activity that increases } \\
\text { core temp for } 2 \text { hours after taking dose }\end{array}$ \\
\hline & & Do not consume alcohol in conjunction with dosing \\
\hline & & Aim to take does outside of school \\
\hline & \multirow[t]{4}{*}{ If Cofactors are Present } & Avoid cofactors that may decrease reaction thresholds, when possible \\
\hline & & Postpone dosing if experiencing fever or viral infection \\
\hline & & Temporarily decrease the daily OIT dose \\
\hline & & Hold OIT daily dosing in case of acute, severe GI disease \\
\hline & \multirow{4}{*}{$\begin{array}{l}\text { If Physical or Psychological Aversion to } \\
\text { Allergen Dose Develops }\end{array}$} & Change the delivery vehicle (may mix with other non-offending foods) \\
\hline & & Change the dietary form of allergen to ingest (eg nut vs nut butter vs nut milk) \\
\hline & & Re-motivate and encourage compliance \\
\hline & & Decrease daily dose when needed as a last resort \\
\hline \multirow{7}{*}{$\begin{array}{l}\text { Treatment- } \\
\text { Related } \\
\text { AEs }\end{array}$} & \multirow[t]{2}{*}{$\begin{array}{l}\text { Mild symptoms (eg oropharyngeal itching, } \\
\text { abdominal pain) }\end{array}$} & $\begin{array}{l}\text { In case of uncomfortable symptoms, continue at the same dose level while } \\
\text { attempting temporary pre-dosing with oral antihistamine }\end{array}$ \\
\hline & & Determine whether cofactors are involved and address accordingly \\
\hline & \multirow[t]{3}{*}{ Anaphylaxis } & Prioritization of symptom treatment and stabilization \\
\hline & & Daily dose adjustment (determine how many steps to down dose) \\
\hline & & Ensure patient has current, unexpired epinephrine injector, and knows proper use \\
\hline & \multirow{2}{*}{$\begin{array}{l}\text { Non-lgE-mediated allergic reactions: suspected } \\
\text { EoE and symptoms such as recurrent nausea, } \\
\text { emesis, abdominal pain, refusal to eat, or } \\
\text { dysphagia }\end{array}$} & Refer to Gl specialist or specialist in EoE for further guidance \\
\hline & & Discontinue OIT dosing \\
\hline
\end{tabular}

Abbreviations: AE, adverse event; EoE, eosinophilic esophagitis; GI, gastrointestinal; OIT, oral immunotherapy.

previously tolerated OIT dose levels, the provider may transiently reduce the ingested allergen dose or encourage pre-dosing with antihistamine treatment followed by termination of the antihistamine to assess recurrence of allergic symptoms. For severe reactions, a reduction to at least the last tolerated dose is expected for one or more weeks before resuming dose escalation.

Clinicians should consider the following factors when performing OIT in children:

- There is no current, convincing evidence of a difference between food allergens in regard to OIT safety and efficacy. ${ }^{64}$
- The rate of AEs is higher during up-dosing phase, with decreasing prevalence during maintenance dosing. ${ }^{26,32}$

- Certain cofactors ${ }^{67}$ could decrease the reactive threshold for AEs (Table 2). These cofactors may influence some individuals, but not all. Education for all participants undergoing OIT is important. These may include:

- Fever and viral infections.

- Physical activity within 30-60 minutes prior to or 2 hours after dosing.

- Menstruation.

- Alcohol use surrounding OIT dosing. 
Clinical Considerations: Providers should take the opportunity to re-educate patients and their families on the $A E$ management during each visit, such as ensuring the patient has an emergency kit with two current epinephrine auto-injectors and that they and those around them are trained in their use. To ensure children, especially in adolescence, remain compliant with the treatment after facing allergic symptoms and set-backs, clinicians must promptly address any AEs and resulting anxiety, explain and educate on allergenic cofactors, actively adjust doses when appropriate, and re-motivate the patients and families to continue with the treatment plan when needed.

\section{Quality of Life}

As adverse events are commonplace with OIT, QoL during and after OIT treatment is a critical aspect to consider. Epstein-Rigbi et al administered the Food Allergy Quality of Life Questionnaire-Parental Form (FAQLQ-PF) to parents of children undergoing OIT, as well as to those in a control group who were not. ${ }^{68}$ At both partial and full maintenance dose, FAQLQ-PF scores significantly improved in total score, emotional impact, food anxiety, and social and dietary limitation. There was no change in the control group. While some patient's QoL decreased during the up-dosing stage, a significant improvement was seen once the maintenance dose was reached. Furthermore, a recent meta-analysis showed that both OFCs and OIT are associated with an improvement in health-related quality of life. ${ }^{69}$

Although OIT can be a challenging process, the way in which information is conveyed by healthcare providers can change the way patients and families interpret and react to symptoms. The traditional view of symptoms as side effects of treatment is commonly associated with discouragement and interpretation that the symptoms are a sign that the treatment is not successful. ${ }^{70}$ In a recent study, an alternative "symptoms as positive signals" (SAPS) approach was employed wherein patients were educated that non-life-threatening symptoms can signal treatment progression into desensitization and improved outcomes. Peanut allergic patients aged 7-17 years in the SAPS group had significantly less anxiety and symptoms with dose increase, better adherence to dosing routine, and greater increases in immune biomarkers related to desensitization compared with the control. Evidently, patient mindset can play a role in the success of medical treatment and should be a consideration when administering OIT. The group format of the study additionally enabled patients and their families to gain emotional support while sharing and learning practical strategies they could implement. Adopting similar strategies could boost rates of OIT completion and create more positive patient mindsets.
Clinical Considerations: While the up-dosing phase can be a difficult and stressful time for patients and their families, it is reassuring to know that quality of life has been shown to significantly improve during the maintenance phase. Adopting a SAPS approach may decrease OIT-related anxiety and improve adherence.

\section{Future Directions}

It may be difficult for many children and adolescents to understand the long-term benefits of completing OIT treatments, which require substantial time investment and effort with potentially undesirable symptoms along the way. Therefore, it could be beneficial to provide innovative options to alleviate these symptoms and support those children throughout their FA treatment plan. For example, children could use virtual or augmented reality specifically programmed to enhance their experience during emotionally distressing OFCs. Additionally, both the treatment team and patients could benefit from remote OIT homedosing progress and symptom tracking via web-based applications to track treatment adherence and address OITassociated symptoms to allow for earlier intervention, which ultimately may improve OIT results. ${ }^{71}$

Clinical Considerations: Exciting ways to improve the OIT experience for patients are on the horizon, including virtual reality while dosing. Smart phone applications for monitoring could also be utilized to support the OIT journey.

\section{Conclusions}

Despite the risks associated with OIT, an argument can be made that the benefit of desensitization outweighs the risk of accidental exposure and burden on QoL in those maintaining a strict food avoidance diet with reactive care. Patient and provider communication, thorough education, and adopting a shared decision-making process are vital in facilitating successful outcomes in OIT.

\section{Abbreviations}

AE, adverse event; CM, cow's milk; EoE, eosinophilic esophagitis; FA, food allergy; FAQLQ-PF, Food Allergy Quality of Life Questionnaire-Parental Form; Ig, immunoglobulin; IL, interleukin; mOIT, multi-allergen oral immunotherapy; OFC, oral food challenge; OIT, oral immunotherapy; POIT, peanut oral immunotherapy; QoL, quality of life; SAPS, symptoms as positive signals; sIgE, specific immunoglobulin E; SU, sustained unresponsiveness. 


\section{Acknowledgments}

We thank Dr. Vanitha Sampath and Ms. Angela Hy for their help with this manuscript preparation.

\section{Disclosure}

All other authors report no conflicts of interest in this work. Dr. Chinthrajah receives grant support from Consortium for Food Allergy Research (CoFAR), National Institute of Allergy and Infectious Diseases (NIAID), Food Allergy Research \& Education (FARE), NIH, Aimmune, DBV Technologies, Astellas, Novartis, and Regeneron, and is an advisory board member for Alladapt Immunotherapeutics, Novartis, Sanofi, and Genentech. Dr. Long reports personal fees from COUR Pharmaceutical Development Company, Inc.

\section{References}

1. Gupta RS, Warren CM, Smith BM, et al. The public health impact of parent-reported childhood food allergies in the United States. Pediatrics. 2018;142(6):e20181235. doi:10.1542/peds.2018-1235

2. Loh W, Tang MLK. The epidemiology of food allergy in the global context. Int $J$ Environ Res Public Health. 2018;15(9):2043. doi:10.3390/ijerph15092043

3. Lin CH. Food allergy: what it is and what it is not? Curr Opin Gastroenterol. 2019;35(2):114-118. doi:10.1097/MOG.000000000 0000506

4. Sampath V, Sindher SB, Pinzon AMA, Nadeau KC. Can food allergy be cured? What are the future prospects? Allergy. 2020;75 (6):1316-1326. doi:10.1111/all.14116

5. Anvari S, Anagnostou K. The nuts and bolts of food immunotherapy: the future of food allergy. Children. 2018;5(4):47. doi:10.3390/ children5040047

6. Eapen AA, Lavery WJ, Siddiqui JS, Lierl MB. Oral immunotherapy for multiple foods in a pediatric allergy clinic setting. Ann Allergy Asthma Immunol. 2019;123(6):573-581.e3. doi:10.1016/j. anai.2019.08.463

7. Mori F, Barni S, Liccioli G, Novembre E. Oral immunotherapy (OIT): a personalized medicine. Medicina. 2019;55(10):684. doi:10.3390/medicina55100684

8. Wood RA. Oral immunotherapy for food allergy. J Investig Allergol Clin Immunol. 2017;27(3):151-159. doi:10.18176/jiaci.0143

9. Sugiura S, Kitamura K, Makino A, et al. Slow low-dose oral immunotherapy: threshold and immunological change. Allergol Int. 2020;69(4):601-609. doi:10.1016/j.alit.2020.03.008

10. Palosuo K, Karisola P, Savinko T, Fyhrquist N, Alenius H, Mäkelä MJ. A randomized, open-label trial of hen's egg oral immunotherapy: efficacy and humoral immune responses in 50 children. J Allergy Clin Immunol Pract. 2021;9(5):1892-1901.e1. doi:10.1016/ j.jaip.2021.01.020

11. Romantsik O, Tosca MA, Zappettini S, Calevo MG. Oral and sublingual immunotherapy for egg allergy. Cochrane Database Syst Rev. 2018;4(4):Cd010638.

12. Inuo C, Tanaka K, Suzuki S, et al. Oral immunotherapy using partially hydrolyzed formula for cow's milk protein allergy: a randomized, controlled trial. Int Arch Allergy Immunol. 2018;177 (3):259-268. doi:10.1159/000490804

13. Soller L, Abrams EM, Carr S, et al. First real-world safety analysis of preschool peanut oral immunotherapy. J Allergy Clin Immunol Pract. 2019;7(8):2759-2767.e5. doi:10.1016/j.jaip.2019.04.010
14. Jones S, Kim E, Nadeau K, et al. Tolerance development following oral immunotherapy (OIT) in 1-3 year old children with peanut allergy: findings from the Immune Tolerance Network (ITN) IMPACT TRIAL. J Allergy Clin Immunol. 2020;145(2):AB338. doi:10.1016/j.jaci.2019.12.067

15. Vickery BP, Vereda A, Casale TB, et al. AR101 oral immunotherapy for peanut allergy. N Engl J Med. 2018;379(21):1991-2001.

16. Hourihane JOB, Beyer K, Abbas A, et al. Efficacy and safety of oral immunotherapy with AR101 in European children with a peanut allergy (ARTEMIS): a multicentre, double-blind, randomised, placebo-controlled Phase 3 trial. Lancet. 2020;4(10):728-739.

17. Siri D, Kachru R, Griffin N, Vereda A, Smith A, Sher E. Improved tolerability and continued immunomodulation among subjects aged 4-17 years following 12 or 18 months of daily therapeutic AR101 dosing. J Allergy Clin Immunol. 2020;145(2):AB133. doi:10.1016/j. jaci.2019.12.527

18. Vickery BP, Vereda A, Nilsson C, et al. Continuous and daily oral immunotherapy for peanut allergy: results from a 2-year open-label follow-on study. J Allergy Clin Immunol Pract. 2021;9(5):18791889.e14. doi:10.1016/j.jaip.2020.12.029

19. U.S. Food \& Drug Administration. Palforzia. Available from: https:// www.fda.gov/vaccines-blood-biologics/allergenics/palforzia. Accessed September 3, 2021.

20. Bégin P, Winterroth LC, Dominguez T, et al. Safety and feasibility of oral immunotherapy to multiple allergens for food allergy. Allergy Asthma Clin Immunol. 2014;10(1):1. doi:10.1186/1710-1492-10-1

21. Gasich L, Fergeson J, Ly J. Multi-food oral immunotherapy as safe and effective as single food therapy. $J$ Allergy Clin Immunol. 2020;145(2):AB133. doi:10.1016/j.jaci.2019.12.528

22. Vickery BP, Berglund JP, Burk CM, et al. Early oral immunotherapy in peanut-allergic preschool children is safe and highly effective. $J$ Allergy Clin Immunol. 2017;139(1):173-181.e8. doi:10.1016/j. jaci.2016.05.027

23. Du Toit G, Roberts G, Sayre PH, et al. Randomized trial of peanut consumption in infants at risk for peanut allergy. $N$ Engl $J$ Med. 2015;372(9):803-813. doi:10.1056/NEJMoa1414850

24. Vickery BP, Scurlock AM, Kulis M, et al. Sustained unresponsiveness to peanut in subjects who have completed peanut oral immunotherapy. J Allergy Clin Immunol. 2014;133(2):468-475. doi:10.1016/j.jaci.2013.11.007

25. Nagakura KI, Yanagida N, Sato S, et al. Low-dose oral immunotherapy for children with anaphylactic peanut allergy in Japan. Pediatr Allergy Immunol. 2018;29(5):512-518. doi:10.1111/pai.12898

26. Chinthrajah RS, Purington N, Andorf S, et al. Sustained outcomes in oral immunotherapy for peanut allergy (POISED study): a large, randomised, double-blind, placebo-controlled, Phase 2 study. Lancet. 2019;394(10207):1437-1449. doi:10.1016/S0140-6736(19)31793-3

27. Escudero C, Rodríguez Del Río P, Sánchez-García S, et al. Early sustained unresponsiveness after short-course egg oral immunotherapy: a randomized controlled study in egg-allergic children. Clin Exp Allergy. 2015;45(12):1833-1843. doi:10.1111/cea.12604

28. Nachshon L, Goldberg MR, Katz Y, Levy MB, Elizur A. Long-term outcome of peanut oral immunotherapy-real-life experience. Pediatr Allergy Immunol. 2018;29(5):519-526. doi:10.1111/pai.12914

29. Andorf S, Manohar M, Dominguez T, et al. Observational long-term follow-up study of rapid food oral immunotherapy with omalizumab. Allergy Asthma Clin Immunol. 2017;13:51. doi:10.1186/s13223-0170223-8

30. Yee CSK, Albuhairi S, Noh E, et al. Long-term outcome of peanut oral immunotherapy facilitated initially by omalizumab. J Allergy Clin Immunol Pract. 2019;7(2):451-461.e7. doi:10.1016/j. jaip.2018.09.015

31. Itazawa T, Adachi Y, Takahashi $\mathrm{Y}$, et al. The severity of reaction after food challenges depends on the indication: a prospective multicenter study. Pediatr Allergy Immunol. 2020;31(2):167-174. doi:10.1111/ pai. 13140 
32. Burks AW, Jones SM, Wood RA, et al. Oral immunotherapy for treatment of egg allergy in children. $N$ Engl J Med. 2012;367 (3):233-243. doi:10.1056/NEJMoa1200435

33. Grzeskowiak LE, Tao B, Knight E, Cohen-Woods S, Chataway T. Adverse events associated with peanut oral immunotherapy in children - a systematic review and meta-analysis. Sci Rep. 2020;10 (1):659. doi:10.1038/s41598-019-56961-3

34. Babaie D, Mesdaghi M, Nishino M, Mansouri M, Ebisawa M. Oral and sublingual immunotherapy: potential causes for eosinophilic gastrointestinal disorders? Int Arch Allergy Immunol. 2017;172 (2):89-98. doi:10.1159/000457796

35. Lucendo AJ, Arias Á, Tenias JM. Relation between eosinophilic esophagitis and oral immunotherapy for food allergy: a systematic review with meta-analysis. Ann Allergy Asthma Immunol. 2014;113 (6):624-629. doi:10.1016/j.anai.2014.08.004

36. Wright BL, Fernandez-Becker NQ, Kambham N, et al. Baseline gastrointestinal eosinophilia is common in oral immunotherapy subjects with IgE-mediated peanut allergy. Front Immunol. 2018;9:2624. doi:10.3389/fimmu.2018.02624

37. Wright BL, Fernandez-Becker NQ, Kambham N, et al. Gastrointestinal eosinophil responses in a longitudinal, randomized trial of peanut oral immunotherapy. Clin Gastroenterol Hepatol. 2021;16(6):1151-1159.e1114. doi:10.1016/j.cgh.2020.05.019

38. Sindher S, Long AJ, Purington N, et al. Analysis of a large standardized food challenge data set to determine predictors of positive outcome across multiple allergens. Front Immunol. 2018;9:2689. doi:10.3389/fimmu.2018.02689

39. Yanagida N, Sato S, Asaumi T, Ogura K, Ebisawa M. Risk factors for severe reactions during double-blind placebo-controlled food challenges. Int Arch Allergy Immunol. 2017;172(3):173-182. doi:10.1159/000458724

40. Purington N, Chinthrajah RS, Long A, et al. Eliciting dose and safety outcomes from a large dataset of standardized multiple food challenges. Front Immunol. 2018;9:2689. doi:10.3389/ fimmu.2018.02057

41. Chinthrajah RS, Purington N, Andorf S, et al. Development of a tool predicting severity of allergic reaction during peanut challenge. Ann Allergy Asthma Immunol. 2018;121(1):69-76.e62. doi:10.1016/j. anai.2018.04.020

42. Andorf S, Purington N, Block WM, et al. Anti-IgE treatment with oral immunotherapy in multifood allergic participants: a double-blind, randomised, controlled trial. Lancet Gastroenterol Hepatol. 2018;3(2):85-94. doi:10.1016/S2468-1253(17)30392-8

43. Davies AM, Allan EG, Keeble AH, et al. Allosteric mechanism of action of the therapeutic anti-IgE antibody omalizumab. J Biol Chem. 2017;292(24):9975-9987. doi:10.1074/jbc.M117.776476

44. Lin C, Lee IT, Sampath V, et al. Combining anti-IgE with oral immunotherapy. Pediatr Allergy Immunol. 2017;28(7):619-627. doi:10.1111/pai.12767

45. MacGinnitie AJ, Rachid R, Gragg H, et al. Omalizumab facilitates rapid oral desensitization for peanut allergy. J Allergy Clin Immunol. 2017;139(3):873-881 e8. doi:10.1016/j.jaci.2016.08.010

46. Wood RA, Kim JS, Lindblad R, et al. A randomized, double-blind, placebo-controlled study of omalizumab combined with oral immunotherapy for the treatment of cow's milk allergy. J Allergy Clin Immunol. 2016;137(4):1103-1110.e11. doi:10.1016/j. jaci.2015.10.005

47. Sampson HA, Leung DY, Burks AW, et al. A Phase II, randomized, double-blind, parallel-group, placebo-controlled oral food challenge trial of Xolair (omalizumab) in peanut allergy. J Allergy Clin Immunol. 2011;127(5):1309-10.e1. doi:10.1016/j. jaci.2011.01.051

48. Burks AW, Sampson HA, Plaut M, Lack G, Akdis CA. Treatment for food allergy. J Allergy Clin Immunol. 2018;141(1):1-9. doi:10.1016/j. jaci.2017.11.004
49. Schneider LC, Rachid R, LeBovidge J, Blood E, Mittal M, Umetsu DT. A pilot study of omalizumab to facilitate rapid oral desensitization in high-risk peanut-allergic patients. J Allergy Clin Immunol. 2013;132(6):1368-1374. doi:10.1016/j.jaci.2013.09.046

50. Bégin P, Dominguez T, Wilson SP, et al. Phase 1 results of safety and tolerability in a rush oral immunotherapy protocol to multiple foods using omalizumab. Allergy Asthma Clin Immunol. 2014;10(1):7. doi:10.1186/1710-1492-10-7

51. Nadeau KC, Schneider LC, Hoyte L, Borras I, Umetsu DT. Rapid oral desensitization in combination with omalizumab therapy in patients with cow's milk allergy. J Allergy Clin Immunol. 2011;127 (6):1622-1624. doi:10.1016/j.jaci.2011.04.009

52. Andorf S, Purington N, Kumar D, et al. A phase 2 randomized controlled multisite study using omalizumab-facilitated rapid desensitization to test continued vs discontinued dosing in multifood allergic individuals. EClinicalMedicine. 2019;7:27-38. doi:10.1016/j. eclinm.2018.12.006

53. Frischmeyer-Guerrerio PA, Masilamani M, Gu W, et al. Mechanistic correlates of clinical responses to omalizumab in the setting of oral immunotherapy for milk allergy. J Allergy Clin Immunol. 2017;140 (4):1043-1053.e8. doi:10.1016/j.jaci.2017.03.028

54. Sousa AF, Yang A, Mendes CG, Boufleur K, Torres P, Salles-Cunha P. Safety of oral immunotherapy associated with omalizumab in severe cow's milk allergy. J Allergy Clin Immunol. 2020;145(2): AB133. doi:10.1016/j.jaci.2019.12.529

55. Takahashi M, Soejima K, Taniuchi S, et al. Oral immunotherapy combined with omalizumab for high-risk cow's milk allergy: a randomized controlled trial. Sci Rep. 2017;7(1):17453. doi:10.1038/s41598-017-16730-6

56. Long A, Borro M, Sampath V, Chinthrajah RS. New developments in non-allergen-specific therapy for the treatment of food allergy. Curr Allergy Asthma Rep. 2020;20(1):3. doi:10.1007/s11882-020-0897-8

57. Sastre J, Dávila I. Dupilumab: a new paradigm for the treatment of allergic diseases. J Investig Allergol Clin Immunol. 2018;28 (3):139-150. doi:10.18176/jiaci.0254

58. Macdougall JD, Burks AW, Kim EH. Current insights into immunotherapy approaches for food allergy. Immunotargets Ther. 2021;10:1-8. doi:10.2147/ITT.S266257

59. Dupilumab and milk OIT for the treatment of cow's milk allergy. NLM identifier: NCT04148352. Available from: https://clinicaltrials. gov/ct2/show/NCT04148352. Accessed September 03, 2021.

60. Study in pediatric subjects with peanut allergy to evaluate efficacy and safety of dupilumab as adjunct to AR101 (peanut oral immunotherapy). NLM identifier: NCT03682770. Available from: https:/clinicaltrials. gov/ct2/show/NCT03682770. Accessed September 03, 2021.

61. Clinical study using biologics to improve multi OIT outcomes. NLM identifier: NCT03679676. Available from: https://clinicaltrials.gov/ ct2/show/NCT03679676. Accessed September 03, 2021.

62. Arasi S, Caminiti L, Crisafulli G, et al. The safety of oral immunotherapy for food allergy during maintenance phase: effect of counselling on adverse reactions. World Allergy Organ J. 2019;12 (1):100010. doi:10.1016/j.waojou.2018.11.008

63. Chinthrajah RS, Cao S, Dunham T, et al. Oral immunotherapy for peanut allergy: the pro argument. World Allergy Organ J. 2020;13 (8):100455. doi:10.1016/j.waojou.2020.100455

64. Bégin P, Chan ES, Kim H, et al. CSACI guidelines for the ethical, evidence-based and patient-oriented clinical practice of oral immunotherapy in IgE-mediated food allergy. Allergy Asthma Clin Immunol. 2020;16(1):20. doi:10.1186/s13223-020-0413-7

65. Wasserman RL, Jones DH, Windom HH, et al. Reaching for best practices in food oral immunotherapy: report on the second annual food allergy support team meeting. Ann Allergy Asthma Immunol. 2019;123(2):129-130.e3. doi:10.1016/j.anai.2019.05.002

66. Wasserman RL, Jones DH, Windom HH. Oral immunotherapy for food allergy: the FAST perspective. Ann Allergy Asthma Immunol. 2018;121(3):272-275. doi:10.1016/j.anai.2018.06.011 
67. Versluis A, Van Os-medendorp H, Kruizinga AG, Blom WM, Houben GF, Knulst AC. Cofactors in allergic reactions to food: physical exercise and alcohol are the most important. Immun Inflamm Dis. 2016;4(4):392-400. doi:10.1002/iid3.120

68. Epstein-Rigbi N, Goldberg MR, Levy MB, Nachshon L, Elizur A. Quality of life of food-allergic patients before, during, and after oral immunotherapy. J Allergy Clin Immunol Pract. 2019;7(2):429-436. e2. doi:10.1016/j.jaip.2018.06.016

69. Cao S, Borro M, Alonzi S, Sindher S, Nadeau K, Chinthrajah RS. Improvement in health-related quality of life in food-allergic patients: a meta-analysis. J Allergy Clin Immunol Pract. 2021;9(10):3705-3714.
70. Howe LC, Leibowitz KA, Perry MA, et al. Changing patient mindsets about non-life-threatening symptoms during oral immunotherapy: a randomized clinical trial. J Allergy Clin Immunol Pract. 2019;7(5):1550-1559. doi:10.1016/j.jaip.2019.01.022

71. Nachshon L, Goldberg MR, Elizur A, Levy MB, Schwartz N, Katz YA. Web site-based reporting system for monitoring home treatment during oral immunotherapy for food allergy. Ann Allergy Asthma Immunol. 2015;114(6):510-515. doi:10.1016/j.anai.2015.04.007

\section{Publish your work in this journal}

The Journal of Asthma and Allergy is an international, peer-reviewed open-access journal publishing original research, reports, editorials and commentaries on the following topics: Asthma; Pulmonary physiology; Asthma related clinical health; Clinical immunology and the immunological basis of disease; Pharmacological interventions and

Submit your manuscript here: https://www.dovepress.com/journal-of-asthma-and-allergy-journal new therapies. The manuscript management system is completely online and includes a very quick and fair peer-review system, which is all easy to use. Visit http://www.dovepress.com/testimonials.php to read real quotes from published authors. 